\title{
Capsicum chinense Jacq. (Bhut Jolokia) - rich source of capsaicin with wide application and economic potential
}

\section{Biswadeep Gogoi*}

Department of Botany, Gauhati University, Guwahati-781014, Assam, India.

Received: 2017-06-15; Accepted: 2017-06-26

\begin{abstract}
Bhut jolokia, which is a cultivar of Capsicum cbinense Jacq. is known to the world for its high capsaicinoids content. While wild C. chinense forms may be found in eastern lowland of South America, bhut jolokia is grown in the northeastern states of India. Evidences show that bhut jolokia has interspecific origin with introgression of genes of $C$. frutecens into C. cbinense a natural hybridisation. The fruit of the plant and its leaves has been used as ethnobotanical medicine in different parts of the world. Phytochemical analysis has shown that the fruit is rich in capsaicinoids, which is the reason for its high pungency. Capsaicin and dihydrocapsaicin are the two major capsaicinoids adding pungency to chilli. Higher the capsaicin higher is the pungency. Recent studies has shown wide medicinal applications of capsaicin such as pain relief, anti-obesity treatment, as an antioxidant, antimicrobial agent and even as anticancer molecule. The government of Nagaland has patent rights and geographical indications for naga chilli, which will certainly help in the economic prospect of the region from its cultivation. Thus, this review is an attempt to highlight the latest research and developments in bhut jolokia, which has a huge economic potential to prosper the northeastern region of India.
\end{abstract}

Keywords: Bhut jolokia, Capsicum chinense Jacq., Capsaicinoids, Capsaicin, Medicinal, Patent rights

\section{Introduction}

The genus Capsicum belongs to the family Solanaceae (Nightshades) and the fruits of the plant are used widely as a spice to add flavour in food, natural plant colour, and pharmaceutical ingredient and as sprays for riot control and self-defence. The genus consists of about 32 species, among which the five major cultivated species are Capsicum annum L., Capsicum chinense Jacq., Capsicum frutescens L., Capsicum baccatum L., and Capsicum pubescens Ruiz and $\mathrm{Pav}[1,2]$. The number might increase in near future as on a regular basis, new species are being identified and added to the list. Capsicum is believed to be originated in tropical South America [3], but are now grown worldwide. Christopher Columbus has been given the credit for introducing chilli to Europe and subsequently to Africa and Asia [4]. In India, C. annuum is most widely cultivated, whereas, the cultivation of $C$. frutescens, $C$. chinense, and $C$. baccatum is not common and are usually restricted to homestead gardening in different regions [5]. The northeastern part of India consisting of states like Arunachal Pradesh, Assam, Manipur, Meghalaya, Mizoram, Nagaland, Sikkim and Tripura is considered as hot-spot for chilli diversity due to its unique ecological conditions. A Capsicum landrace (Bhut Jolokia) from this region has been identified as the world's hottest known chili pepper with Scoville heat units (SHU's) rating of 1,001,304, a widely used heat measurement of chili peppers [6]. A number of variants of this chilli were noted in the northeastern region of India with different local names such as Naga chilli in Nagaland, Bhut Jolokia in Assam, and U-Morok in Manipur [7, 8]. Earlier this Capsicum landrace was identified as Capsicum frutescens Linn., however, its morphological characters resembles to Capsicum chinense species which is known to produce hottest chilli peppers in past. Later the dilemma on authenticity of Bhoot Jolokia was established through RAPD analysis as Capsicum chinense with inclusion of genes of Capsicum frutescens through natural hybridization by cross-pollination between species or any other method [6]. Thus, the presence of RAPD markers in 'Bhut Jolokia' that are specific to $C$. chinense and C. frutescens suggests an interspecific origin for 'Bhut Jolokia'.

\begin{tabular}{lcl}
\multicolumn{2}{l}{ Taxonomic Classification } \\
Kingdom & - & Plantae \\
Division & - & Magnoliophyta \\
Class & - & Magnoliopsida \\
Order & - & Solanales \\
Family & - & Solanaceae \\
Genus & - & Capsicum \\
Species & - & C. chinense Jacq.
\end{tabular}

\section{Synonyms}

Capsicum sinense Murray

Capsicum toxicarium Poepp. ex Fingerh.

\footnotetext{
*Corresponding Author:

Biswadeep Gogoi*

Department of Botany,

Gauhati University, Guwahati-781014,

Assam, India.

E-mail: biswa 406@,rediffmail.com
} 


\section{Common Name \\ Assamese - Bhut Jolokia \\ English - Ghost Pepper \\ Manipuri - Umorok \\ Nagaland - Naga King Chilli}

\section{Habitat and Distribution}

The plant is an erect bushy herbaceous annual plant, which can attain a height of $57-129 \mathrm{~cm}$. It can grow even more in semi-perennial situation. The plant is a self-pollinated species, but there are record, which shows considerable outcrossing in chillies with the aid of insect pollinators ranging from 7 to $91 \%[9,10,11]$. Wild $C$. chinense forms may be found in eastern lowland of South America. Bhut jolokia is grown mainly in the state of Nagaland, Assam and Manipur and to some extent in Mizoram, Arunachal Pradesh and Meghalaya. It is also cultivated in the northeastern region of Bangladesh [12].

\section{Morphology}

Stem colour dark green.

Leaves have characteristic crinkle look as found in other C.chinense species, green in colour, ovate in shape.

Flowers grow like pendant in pair per axil, with creamy white corolla, anthers are blue and filaments are purple.

Fruits are elongated, sub-conical to conical in shape, $5-8 \mathrm{~cm}$ in length with an undulating surface, which on maturity changes colour from green to red.

Seed colour light brown, wrinkled.

\section{Ethnobotanical Uses}

The fruit of the plant, which is known for its strong pungency, has also been used in many ethnobotanical uses. The fruit if consumed in low quantity on a regular basis can help relief to asthma patients. The Maya people had also the tradition of using Capsicum to cure asthma cough and sore throat [4]. Regular consumption of the fruit in small quantity is also good for gastrointestinal disorders. The hot property of the fruit helps to tone the muscle and alleviating pain after hard work. Hot infusions of the fruit is used to treat toothache and muscle pain. There is also use of the tender leaves of the plant as a fine paste over boils, which helps in easy removal of pus [13]. In the Amazon region, the fruit is used as a remedy for stomachache and to cure hangover or hallucination. A decoction of the fruits and leaves are also used in Eastern Nicargua in postpartum abdominal and back pain, fever, respiratory and pulmonary disorder, skin rashes and sores $[14,15,16]$.

\section{Phytochemical Profile}

The hot flavour of chillies is due to the presence of a group of closely related compounds called capsaicinoids. Capsaicinoids are amides produced by Capsicum species. These secondary metabolites are responsible for the strong and hot taste of the fruits, also known as pungency. Capsaicinoids consist of compounds that differ in the structure of branched fatty acid (acyl) moieties attached to the benzene ring of vanillylamine. Any variation in the chemical structures of the capsaicinoids, including the structure of the acyl moiety, affects the degree and the level of the pungency [17].

Capsaicin (8-methyl- $N$-vanillyl-6-nonenamide) and dihydrocapsaicin are the two major capsaicinoids found in hot peppers (more than $90 \%$ of the total capsaicinoids), whereas nordihydrocapsaicin, homodihydrocapsaicin, and homocapsaicin are present in lower amounts [18]. Levels of total capsaicinoids can be converted to Scoville heat units (SHU), a measurement for pungency developed by Wilbur Scoville. By definition, one part per million (ppm) of capsaicin has a pungency of $15 \mathrm{SHU}$. In the first ever report on the pungency of bhut jolokia, it was reported to be $855,000 \mathrm{SHU}$ [19]. Subsequently in 2007, pungency was recorded as $1,001,304 \mathrm{SHU}$ [6]. In a recent study of 2015, the average capsaicinoid content within 92 bhut jolokia accessions was $41.79 \mathrm{mg} / \mathrm{g}$ corresponding to 668,649 SHU. The capsaicinoid content among 92 accessions of bhut jolokia from northeast India varied from 11.95 to $72.05 \mathrm{mg} / \mathrm{g}$ with corresponding pungency levels of 191,135 1,152,832 SHU [20].

\section{Economic Prospect}

Correlation analysis between two major capsaicinoids, capsaicin and dihydrocapsaicin had shown a highly significant and positive correlation between capsaicin and dihydrocapsaicin. It clearly indicates that accumulation of capsaicin enhances the accumulation of dihydrocapsaicin irrespective of the genotype. The concentration of capsaicin was found to be higher as compared to that of dihydrocapsaicin in all the Capsicum with high pungency [20]. Therefore, the higher the pungency higher is the content of capsaicin, which has many established pharmacological activity. Capsaicin has a wide range of medicinal applications such as in pain relief [21, 22], anti-obesity treatment [23], as an antioxidant $[24,25]$, antimicrobial agent $[26,27]$ and as anticancer molecule [28]. There has been a high demand for this crop in both domestic markets as well as in abroad. The state government of Nagaland has got the patent rights of Naga King Chilli and got Geographical indication from Government of India under Registration and Protection Act, 1999. Most of the chilli species and varieties cultivated in India contain around $1 \%$ capsaicin but Naga chilli has around $2-4 \%$ capsaicin as reported by various researchers [19, 29]. It shows the fact that this chilli has high value for capsaicin content over the chillies grown in other parts of the country and hence can be used exclusively for capsaicin extraction. Low capsaicinoid content in commercial cultivars of Capsicum is not favourable due to increased cost of extraction of capsaicin. 
Consequently, bhut jolokia with high capsaicinoid content has not only overcome this bottleneck but also created a demand in the world market for itself.

\section{Conclusion}

Bhut jolokia found in the northeastern states of India has been known to the world for its high capsaicinoid content. Fruit of the plant has ethnobotanical uses in different parts of the world. High capsaicin content and global demand has made the cultivation of this species of Capsicum a rewarding for the farmers of Northeastern India. Still the marketing of bhut jolokia follows a traditional trend though there are enough opportunity to utilize this crop for economic prosperity of the region.

Thus, this review attempted to look into the latest research and developments in bhut jolokia, which has a huge economic potential and can help in prospering the northeastern part of India.

\section{Acknowledgement}

The author is grateful to the authorities of Department of Botany, Gauhati University for their support.

\section{References}

1. Barboza, GE. "Lectotypifications, synonymy, and a new name in Capsicum (Solanoideae, Solanaceae)". PbytoKeys 2 (2011): 23-38.

2. Basu, SK, and AK De. "The Genus Capsicum". Capsicum. Ed. AK De. Vol. 33. London: Taylor \& Francis, Ltd., 2003. 1-15.

3. Greenleaf, WH. "Pepper breeding". Breeding vegetable crops. Ed. Bassett MJ. Westport: AVI Publishing Co., 1986. 67-134

4. Bosland, PW. "Capsicums: innovative uses of an ancient crop". Progress in New Crops. Ed. Janick J. Arlington, VA: ASHS Press, 1996. 479-487.

5. Reddy, MK, A Srivastava, S Kumar, R Kumar, N Chawda, AW Ebert, and M Vishwakarma. "Chilli (Capsicum annumm L.) breeding in India: An overview". SABRAO Journal of Plant Breeding and Genetics 46.2 (2014): 160-173.

6. Bosland, PW and JB Baral. "Bhut Jolokia: The World's Hottest Known Chile Pepper is a Putative Naturally Occurring Interspecific Hybrid". Hortscience 42.2 (2007): 222-224.

7. Sanatombi, K, S Sen-Mandi, and GJ Sharma. "DNA profiling of Capsicum landraces of Manipur". Scientia Horticulturae $\quad 124.3 \quad$ (2010): $\quad 405-408$. http://dx.doi.org/10.1016/j.scienta.2010.01.006

8. Verma, PK, KK Rawat, N Das, and B Pradhan. "A botanical enigma of India's hottest chilli Bhoot Jolokia (Capsicum cbinense Jacq)". New York Science Journal 6 (2013): 49-51.
9. Odland, ML, and AM Porter. "A study of natural crossing in pepper (Capsicum frutescens L.)". Journal of the American Society for Horticultural Sciences 38 (1941): $585-588$

10. Franceschetti, U. "Natural cross pollination in pepper (Capsicum annum L.)". Proceedings of Eucarpia Meeting on Genetic and Breeding of Capsicum. Italy: University of Turin (P), 1971. 346-353

11. Tanksley, SD. "High rates of cross pollination in chile pepper". Hort Science 19 (1984): 580-582

12. Bhuyan, MHMB, SML Rahman, R Ara, and JC Sarker. "Evaluation of Naga Chilli (Capsicum cbinense Jacq.) genotypes under North eastern region of Bangladesh". Scientia Agricola 12.1 (2015): 40-45. http://dx.doi.org/10.15192/PSCP.SA.2015.12.1.404 5

13. Bhagowati, RR, and S Chankija. "Genetic variability and traditional practices in Naga King Chilli landraces of Nagaland". Asian Agri-History 3 (2009): 171-180.

14. Coe, FG. "Rama midwifery in eastern Nicaragua". Journal of Ethnopharmacology 117.1 (2008):136-157.

15. Coe, FG, and GJ Anderson. "Ethnobotany of the Miskitu of eastern Nicaragua". Journal of Ethnobiology 17 (1997):171-214.

16. Meghvansi, MK, S Siddiqui, MH Khan, VK Gupta, MG Vairale, HK Gogoi and L Singh. "Naga chilli: A potential source of capsaicinoids with broadspectrum ethnopharmacological applications". Journal of Ethnopharmacology 132 (2010):1-14. doi:10.1016/j.jep.2010.08.034

17. Wang, J, Z Peng, S Zhou, J Zhang, S Zhang, X Zhou, X Zhang and B Peng. "A study of pungency of capsaicinoid as affected by their molecular structure alteration”. Pharmacol. Pharm. 2 (2011): 109115.

18. Howard, LR, and REC Wildman. "Antioxidant vitamin and phytochemical content of fresh and processed pepper fruit (Capsicum annum)". Handbook of nutraceuticals and functional foods. Ed. Wildman, REC. Boca Raton, FL: CRC Press, 2007. 165-191.

19. Mathur, R, RS Dangi, SC Dass, and RC Malhotra. "The hottest chilli variety in India". Current Science 79 (2000): 287-288.

20. Islam, MA, SS Sharma, P Sinha, MS Negi, B Neog, and SB Tripathi. "Variability in capsaicinoid content in different landraces of Capsicum cultivated in northeastern India". Scientia Horticulturae 183 (2015): 66-71

21. Rout, SD, and SK Panda. "Ethnomedicinal plant resources of Mayurbhanj district, Orissa". Indian J. Tradit. Knowl. 9 (2010): 68-72.

22. Yamamoto, S, and E Nawata. "Use of Capsicum frutescens $\mathrm{L}$. by the indigenous peoples of Taiwan and the Batanes islands". Econ. Bot. 63 (2009): 43-59. 
23. Snitker, S, Y Fujishima, H Shen, S Ott, X Pi-Sunyer, Y Furuhata, H Sato, and M Taka-hashi. "Effects of novel capsinoid treatment on fatness and energymetabolism in humans: possible pharmacogenetic implications". Am. J. Clin.Nutr. 89 (2009): 45-50.

24. Henderson, DE, AM Slickman, and SK Henderson. "Quantitative HPLC deter-mination of the antioxidant activity of capsaicin on the formation of lipidhydroperoxides of linoleic acid: a comparative study against BHT and melatonin". J. Agric. Food Chem. 47 (1999): 2563-2570.

25. Kogure, K, S Goto, M Nishimura, M Yasumoto, K Abe, C Ohiwa, H Sassa, T Kusumi, and H Terada. "Mechanism of potent antiperoxidative effect of capsaicin”. Biocbim. Biophys. Acta 1573 (2002): 84-92.

26. Cowan, MM. "Plant products as antimicrobial agents”. Clin. Microbiol. Rev. 12 (1999): 564-582.
27. Jones, NL, S Shabib, and PM Sherman. "Capsaicin as an inhibitor of the growth of the gastric pathogen Helicobacter pylori”. FEMS Microbiol. Lett. 146 (1997): 223-227.

28. Jung, MY, HJ Kang, and A Moon. "Capsaicininduced apoptosis in SK-Hep 1hepatocarcinoma cells involves Bcl-2 downregulation and caspase-3 activation". Cancer Lett. 165 (2001): 139-145.

29. Sanatombi, K, and GJ Sharma. "Capsaicin content and pungency of different Capsicum spp. cultivars". Notulae Botanicae Horti Agrobotanici Cluj-Napoca 36.2 (2008): 89-90

\section{Cite this article as:}

Biswadeep Gogoi. Capsicum chinense Jacq. (Bhut Jolokia) - rich source of capsaicin with wide application and economic potential. Annals of Plant Sciences 6.8 (2017) pp. 1664-1667.

doi: http://dx.doi.org/10.21746/aps.2017.08.003

Source of support: Department of Botany, Gauhati University, India. Conflict of interest: Nil 